\title{
Development of the Assessment Framework for the Environmental Impacts in Construction
}

\author{
Tahoon Hong ${ }^{1}$, Changwoon $\mathrm{Ji}^{2}$, Kwangbok Jeong ${ }^{3}$ and Joowan Park ${ }^{4}$
}

Accepted February 1, 2013

\begin{abstract}
Environmental problems like global warming have now become important issues that should be considered in all industries, including construction. In South Korea, many studies have been conducted to achieve the government's goals of reduction in environmental impacts. However, the research on buildings has only focused on CO2 emission as a research target despite the fact that other environmental impacts resulting from ozone depletion and acidification should also be considered, in addition to global warming. In this regard, this study attempted to propose assessment criteria and methods to evaluate the environmental performance of the structures from various aspects. The environmental impact category can be divided into global impacts, regional impacts, and local impacts. First, global impacts include global warming, ozone layer depletion, and abiotic resource depletion, while regional impacts include acidification, eutrophication, and photochemical oxidation. In addition, noise and vibration occurring in the building construction phase are defined as local impacts. The evaluation methods on the eight environmental impacts will be proposed after analyzing existing studies, and the methods representing each environmental load as monetary value will be presented. The methods presented in this study will present benefits that can be obtained through green buildings with a clear quantitative assessment on structures. Ultimately, it is expected that if the effects of green buildings are clearly presented through the findings of this study, the greening of structures will be actively expanded.
\end{abstract}

Keywords: Life Cycle Assessment, Life Cycle Impact Assessment, Environmental Impact Category, Monetary valuation

\section{INTRODUCTION}

With increasing interest in the environment, many studies designed to select environmental-friendly materials have been carried out to reduce the environmental impacts in building construction. In recent years, research on developing green buildings have been promoted, especially in South Korea, as an effort to reduce environmental impacts. To select environmentalfriendly materials or to widen the construction of green buildings, the values of the materials or those of green buildings must be clearly defined.

LCA is a methodology that evaluates environmental impacts due to the inputs and outputs comprehensively occurring during the life cycle [1], and it can be utilized in the evaluation of structures [2]. Recognizing the importance of LCA, many researchers have exerted efforts to utilize it as a method to evaluate the environmental impacts of constructing buildings [3]. Actually, the US green building council has discussed plans to integrate LCA into the leadership in energy and environmental design (LEED) system [4]. However, most of domestic studies have only considered $\mathrm{CO}_{2}$ emissions to assess environmental load [5-7]. For a clear assessment of the environmental values of green buildings, various environmental impacts caused by building construction, in addition to $\mathrm{CO}_{2}$ emissions, must be evaluated. Since life cycle impact assessment (LCIA) methodologies on life cycle assessment (LCA) define a variety of environmental impact categories and present standards on evaluating each impact, they can be used as criteria for evaluating the environmental impacts of constructing buildings.

Meanwhile, existing LCIA methodologies may not be applicable for the unique building construction because they have not reflected the characteristics of construction. Accordingly, environmental impacts caused by the characteristics of building construction should also be considered. That is, it is necessary to define the environmental impacts occurring in the construction phase, in which the use of energy and equipment is concentrated.

In this study, before presenting a framework for assessing the environmental impacts of building construction, the considerations for environmental impact assessment were first reviewed. Then, various existing LCIA methods were examined, and additional environmental impacts caused by construction activity were investigated. Finally, a framework for assessing environmental impacts in building construction was proposed by integrating the impact categories presented in existing LCIA methods, and additionally defined impact categories.

\footnotetext{
${ }^{1}$ Associate Professor, Department of Architectural Engineering, Yonsei University, Seoul, Korea, hong7@ yonsei.ac.kr (*Corresponding Author)

2 Department of Architectural Engineering, Yonsei University, Seoul, Korea

${ }^{3}$ Department of Architectural Engineering, Yonsei University, Seoul, Korea

${ }^{4}$ Department of Architectural Engineering, Yonsei University, Seoul, Korea
} 


\section{CONSIDERATIONS FOR ENVIRONMENTAL IMPACT ASSESSMENT}

\section{A. Criteria for Characterization Method}

The evaluation methods presented in this study can be utilized as standards to suggest environmental values, in addition to economic values of the building by presenting the evaluation results on the environmental performance of the buildings. Accordingly, the evaluation results on the environmental impacts can be objective and accurate enough to be accepted by the general public or participants in the construction industry. As criteria for the characterization of environmental impacts, the International Reference Life Cycle Data Systems (ILCD) presented the completeness of scope, environmental relevance, scientific robustness and certainty, documentation, transparency and reproducibility, and applicability [8]. This study presents the methods in evaluating the environmental impacts in building construction in consideration of the criteria as defined by ILCD (2010). In other words, the impact categories included in the evaluation methods presented in this study are to include all environmental impacts caused by construction activities. In addition, the methods in evaluating each environmental impact should be made based on the scientific evidence, subsequently helping to present objective and clear results at all times.

Life cycle assessment (LCA) is one of the representative methodologies to present the quantitative environmental impact assessment results based on ISO 14000 series [9]. This LCA methodology can also be utilized in presenting objective and transparent results through the comprehensive evaluation of environmental impacts occurring during the life cycle of the structures [2]. With the recent increase in environmental problems, many studies have been designed to assess environmental impacts using LCA in South Korea [3, 5, 6]. Accordingly, if the method that can assess the environmental impacts in building construction based on LCA methodology is presented, it is thought to meet all the criteria defined in ILCD.

\section{B. Stakeholder Acceptance}

The purpose of evaluating the environmental impacts of buildings in the construction industry is to ultimately reduce environmental impacts by constructing more ecofriendly buildings. To promote the construction of green buildings, the results that can be used to persuade stakeholders must be presented along with the exact evaluation [8]. That is, evaluation results should be recognized by an authoritative body, and they should be easily understood and interpretable not only by professionals, but also by the general public. In addition, to attract the interest of stakeholders, a comparison between environmental impacts and additional costs for green buildings can be made. Since the cost have traditionally been considered an important element of the decision-making process, the best way to persuade nonprofessional stakeholders is to show the effects of green buildings through monetary values. Among many environmental impacts, the most commonly known global warming potential can be represented as "kg-CO2". However, it is difficult for non-professionals to understand the value of the effects of the reduction in units of "kg-CO2". In this regard, it is required to present the evaluation results like kg-CO2 into monetary values.

\section{SELECTION OF ENVIRONMENTAL IMPACT CATEGORY}

\section{A. Characteristics of building construction}

Unlike manufacturing products in the factory, structures have characteristics in the process of construction in requiring the use of construction equipment in the field. In addition, as the number of equipment used in the progress of construction works in the limited space rises, it can affect the living environment of the local area adjacent to the construction site. Accordingly, in conducting effective environmental impact assessment, environmental impacts caused by the characteristics of the building construction activities must be considered, in addition to typical environmental impacts.

Many studies have determined the categories of environmental impacts due to construction [10-15]. Table I shows the environmental impacts from construction activities, as deduced from the literature review. The impact categories deduced from the literature review include not only typical environmental impacts, such as harmful gases or resources, but also problems occurring in the local area adjacent to the construction site, including noise, vibration, falling objects, and traffic problems, which show that environmental problems occurring in the process of building construction should be included in the scope of environmental impact assessment. In this regard, the impact categories presented in Table I must be taken into consideration to evaluate environmental impacts caused by construction activities.

As shown in Table I, many studies define harmful gases, resource consumption, noise, vibration, dust, solid waste, and liquid wastes as environmental impacts. Accordingly, those should be included in the environmental impact category of construction activities. 
TABLE I

ENVIRONMENTAL IMPACT FROM CONSTRUCTION ACTIVITY

\begin{tabular}{|c|c|c|c|c|c|c|c|c|}
\hline \multirow{2}{*}{ Environmental Impact Category } & \multicolumn{7}{|c|}{ Previous Study } & \multirow{2}{*}{$\begin{array}{c}\text { Frequency of } \\
\text { Occurrence }\end{array}$} \\
\hline & A & B & $\mathrm{C}$ & $\mathrm{D}$ & $\mathrm{E}$ & $\mathrm{F}$ & $\mathrm{G}$ & \\
\hline Harmful gases & $*$ & $*$ & & & $*$ & & $*$ & 4 \\
\hline Noises & $*$ & $*$ & & $*$ & $*$ & $*$ & & 5 \\
\hline Solid wastes (pollution) & $*$ & $*$ & $*$ & & $*$ & $*$ & & 5 \\
\hline Liquid wastes (pollution) & $*$ & $*$ & & $*$ & $*$ & $*$ & & 5 \\
\hline Incidents, accidents and potential emergency situations & $*$ & & & & & & & 1 \\
\hline Vibration & $*$ & $*$ & & & $*$ & & & 3 \\
\hline Dust & & $*$ & & $*$ & $*$ & $*$ & & 4 \\
\hline Wildlife and natural features impact & & $*$ & & & & & & 1 \\
\hline Archaeology impacts & & $*$ & & & & & & 1 \\
\hline Resource consumption & & & $*$ & $*$ & $*$ & & $*$ & 4 \\
\hline Ecological loadings & & & $*$ & $*$ & & & & 2 \\
\hline Human health & & & $*$ & $*$ & & & & 2 \\
\hline Landscape & & & & $*$ & & $*$ & & 2 \\
\hline Traffic problem & & & & $*$ & & $*$ & & 2 \\
\hline Odors & & $*$ & & & $*$ & & & 2 \\
\hline Mud & & & & & & $*$ & & 1 \\
\hline Space shortage & & & & & & $*$ & & 1 \\
\hline
\end{tabular}

Note: A; Chen et al. (2000), B; Chen et al. (2005), C; Cole (2000), D; March (1992), E; Shen and Tam (2002), F; Cardoso (2005),

G; Hong et al. (2012)

\section{B. Life cycle impact assessment methodologies}

Life cycle impact assessment (LCIA) is aimed at presenting environmental impacts based on the results of the life cycle inventory analysis. ISO 14042 states that LCI results are classified into environmental impact categories, each with a category indicator [16]. LCIA methods are divided into the problem-oriented approach (midpoint LCIA method) and the damage-oriented approach (endpoint LCIA method), depending on which point is focused on the cause-effect chain [17].

The problem-oriented approach divides the environmental impact categories into environmental issues affected by various substances in the production process of products or services. That is, the problemoriented approach presents impacts that occur in the relatively early stage of the cause-effect chain [18]. Generally, environmental issues of concern, such as global warming, natural resource depletion, stratospheric ozone depletion, acidification, photochemical ozone creation, eutrophication, human toxicity, and aquatic toxicity, are defined as impact categories in the problemoriented approach. As shown in Figure I, ozone layer depletion is defined as the problem caused by CFCs.

The damage-oriented approach aims to present damages on the area of protection (AoP), the endpoint of the cause-effect chain. That is, the damage-oriented approach presents impacts of damage to human health or extinction of species caused by midpoint impacts, such as global warming, ozone depletion, and acidification. For example, ozone layer depletion caused by emissions, such as CFCs or halons, leads to skin cancer, damage to crop productivity, marine life damage, and general damage to human health. In short, the damage-oriented approach presents these final damages as evaluation results.

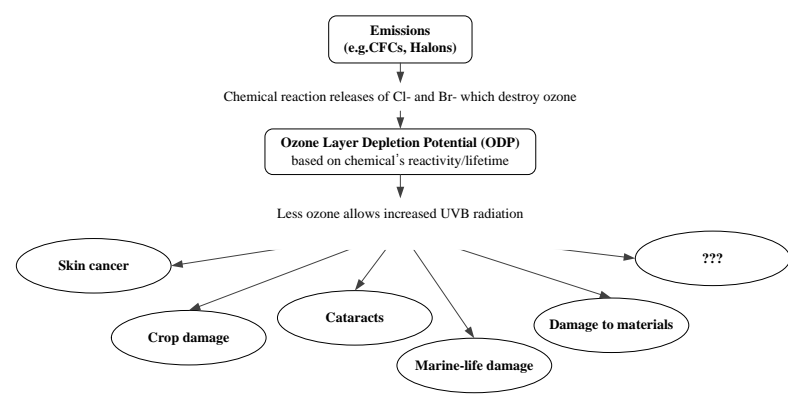

FIGURE I

EXAMPLE of A CAUSE-EFFECT CHAIN ABOUt OZONE LAYER DEPLETION [19]

Up to now, both the problem-oriented and damageoriented methods have been developed by many researchers. The EDIP 2003, CML 2001, TRACI, Environmental Labeling type 3 (EL type 3), and Hong et al. (2012) are typical LCIA methods based on the problem-oriented approach [15, 20-22]. Most problemoriented methods define global warming, ozone layer depletion, acidification, eutrophication, photochemical ozone formation, abiotic depletion, human toxicity, and eco-toxicity as major impact categories.

Eco-Indicator 99 and EPS 2000 are representative LCIA methods based on the damage-oriented approach. The eco-indicator 99 presents the final evaluation results as area of protection (AoP), such as human health, the ecosystem, and natural resources. The AoPs, such as human health, the ecosystem, and natural resources, are presented by using category indicators, such as DALYs (Disability Adjusted Life Years), Potentially Disappeared Fraction (PDF), and resource damage, respectively [23].

Moreover, a single score, the so-called ECO 99 unit, can finally be presented by using weight factors by impact category, as presented in an expert panel analysis. 
Meanwhile, EPS 2000 defines ecosystem production quality in addition to human health, the ecosystem, and natural resources as AoP, and presents the evaluation results through environmental load unit (ELU), the monetary value [24]. The details on EPS 2000 are described in Section 3.3. Table II shows the environmental impacts defined by each LCIA methodology.

Five problem-oriented methods include human toxicity and eco-toxicity in the impact category. However, these impacts can be thought to be identical to damage to human health and the ecosystem specified in the damageoriented methods. Smog formation, land use, and water use is the impact category included only in TRACI. Accordingly, six impacts were included in the midpoint impact category, as defined by Hong et al. (2012). In addition, noise and vibration, presented as impact category in previous studies related to various environmental impacts in building construction, were also defined as midpoint impacts. In previous studies, dust was included as a major impact related to construction activities, but dust was excluded from the impact category in this study since the methods in measuring dust and presenting it as standardized figures were not formulated. After all, eight impacts, including global warming, ozone layer depletion, abiotic depletion, acidification, eutrophication, photochemical ozone production, noise, and vibration, were defined as the midpoint impact category in this study. Global warming, ozone layer depletion, and abiotic depletion are included in the global impacts category; while acidification, eutrophication, and photochemical ozone production are included in the regional impact category. Finally, noise and vibration are included in the local impact category.

TABLE II

ENVIRONMENTAL IMPACT CATEGORY OF EACH LCIA METHODOLOGY

\begin{tabular}{|c|c|c|c|c|c|c|c|}
\hline \multirow[b]{2}{*}{ Environmental Impact Category } & \multicolumn{5}{|c|}{ Problem-oriented Method } & \multicolumn{2}{|c|}{ Damage-oriented Method } \\
\hline & $\begin{array}{l}\text { EDIP } \\
2003\end{array}$ & TRACI & $\begin{array}{l}\text { CML } \\
2001 \\
\end{array}$ & EL type 3 & $\begin{array}{l}\text { Hong et } \\
\text { al. }(2012)\end{array}$ & Eco-Indicator 99 & $\begin{array}{l}\text { EPS } \\
2000 \\
\end{array}$ \\
\hline Global warming & $*$ & $*$ & $*$ & $*$ & $*$ & & \\
\hline Ozone layer depletion & $*$ & $*$ & $*$ & $*$ & $*$ & & \\
\hline Acidification & $*$ & $*$ & $*$ & $*$ & $*$ & & \\
\hline Eutrophication & $*$ & $*$ & $*$ & $*$ & $*$ & & \\
\hline Photochemical ozone formation & $*$ & & $*$ & $*$ & $*$ & & \\
\hline Human toxicity/Human health & $*$ & $*$ & $*$ & & & & \\
\hline Eco-toxicity & $*$ & $*$ & $*$ & & & & \\
\hline Smog formation & & $*$ & & & & & \\
\hline Abiotic depletion & & $*$ & $*$ & $*$ & $*$ & & \\
\hline Land use & & $*$ & & & & & \\
\hline Water use & & $*$ & & & & & \\
\hline Damage to human health & & & & & & $*$ & $*$ \\
\hline Damage to ecosystem & & & & & & $*$ & $*$ \\
\hline Damage to resources & & & & & & $*$ & $*$ \\
\hline Ecosystem production capacity & & & & & & & $*$ \\
\hline
\end{tabular}

\section{Monetization method}

Among many LCIA methodologies, EPS 2000, based on the damage-oriented approach, can present the evaluation results on environmental impacts into monetary values. As shown in Table III, EPS 2000 presents the characterization factors that show which damages are caused by various emissions, based on the scientific evidence [24]. In addition, weighting factors are presented by damage category using the method of willingness to pay (WTP). Since the weighting factor of EPS 2000 signifies monetary value, it is possible to present the global and regional impacts defined earlier as environmental costs.

However, the weighting factors presented in EPS 2000 are made through the survey among residents in Europe. Since there are differences in the economic level and the level of awareness about the environment between South Korea and Europe, the weighting factors must be converted so that they can be used in South Korea. The factors are converted by using the per capita GDP, as shown in Eq. (1). International Monetary Fund (IMF) presented the 2011 GDP per capita of the European Union and South Korea as \$35,116 and \$22,778, respectively. In addition, since ELU presented in EPS 2000 is a unit of EUR, it was converted into KRW by applying the average exchange rate from 2005 to 2010. The five-year average exchange rate presented in the Korea Exchange Bank is 1472.94 KRW per 1 EUR.

$$
\begin{aligned}
& c W F_{i}=o W F_{i} \times \frac{G D P_{\text {capita }} \text { of South Korea }(22,778)}{G D P_{\text {capita }} \text { of European Union }(35,116)} \\
& \times \text { Exchange rate }(1,472.94)
\end{aligned}
$$

Where, $c W F_{i}$ represents the converted weighting factor and $o W F_{i}$ represents the original weighting factor. 
In addition, it is possible to convert the two local impacts into environmental costs by using the compensation criteria for noise and vibration damages, as presented in the National Environmental Dispute Resolution Commission (2008) pursuant to
Environmental Dispute Adjustment Act No. 08955. Table IV shows excessive noise level and calculation criteria for the amount of damages through the damaged period, as presented by the National Environmental Dispute Resolution Commission (2008).

TABLE III

EXAMPLE OF $\mathrm{CO}_{2}$ EMISSION IN EPS 2000

\begin{tabular}{cccc}
\hline Emission & Damage category & Characterization factor & Weighting factor \\
\cline { 2 - 4 } $\mathrm{CO}_{2}$ & Life expectancy (YOLL) & $7.93 \mathrm{E}-07 \mathrm{p} \mathrm{yr} / \mathrm{kg}$ & $85000 \mathrm{ELU} / \mathrm{p} \mathrm{yr}$ \\
& Severe morbidity & $3.53 \mathrm{E}-07 \mathrm{p} \mathrm{yr} / \mathrm{kg}$ & $100000 \mathrm{ELU} / \mathrm{p} \mathrm{yr}$ \\
& Morbidity & $6.55 \mathrm{E}-07 \mathrm{p} \mathrm{yr} / \mathrm{kg}$ & $10000 \mathrm{ELU} / \mathrm{p} \mathrm{yr}$ \\
& Decreasing crop product capacity & $7.56 \mathrm{E}-4 \mathrm{~kg} / \mathrm{kg}$ & $0.15 \mathrm{ELU} / \mathrm{kg}$ \\
& Decreasing wood product capacity & $-0.0405 \mathrm{~kg} / \mathrm{kg}$ & $0.04 \mathrm{ELU} / \mathrm{kg}$ \\
Extinction of species (NEX) & $1.26 \mathrm{E}-14 \mathrm{NEX} / \mathrm{kg}$ & $1.10 \mathrm{E}+11 \mathrm{ELU} / \mathrm{NEX}$ \\
\hline
\end{tabular}

Note: one ELU (Environmental Load Unit) signifies one EUR (currency of the European Union)

TABLE IV

Calculation Criteria for the Amount of Damages by EXCESSive Noise LeVEl ANd Damaged PeRiod PER CAPITA

(Unit: $1,000 \mathrm{KRW})$

\begin{tabular}{lcccccc}
\hline \multirow{2}{*}{ Damaged Period } & \multicolumn{7}{c}{ Excessive Noise Level $(\mathrm{dB}(\mathrm{A}))$} \\
\cline { 2 - 7 } & $0^{\sim} 5$ & $5^{\sim} 10$ & $10^{\sim} 15$ & $15 \sim 20$ & $20 \sim 25$ & $25 \sim$ \\
\hline Within 7 days & 50 & 80 & 130 & 200 & 300 & 400 \\
$7 \sim$ 15 days & 70 & 130 & 220 & 330 & 450 & 570 \\
$15 \sim 30$ days & 80 & 170 & 300 & 430 & 580 & 720 \\
$1 \sim 2$ months & 120 & 250 & 400 & 560 & 720 & 870 \\
$2 \sim 3$ months & 155 & 300 & 460 & 630 & 780 & 960 \\
$3 \sim 4$ months & 190 & 340 & 510 & 670 & 840 & 1010 \\
\hline
\end{tabular}

\section{FRAMEWORK OF ENVIRONMENTAL IMPACT ASSESSMENT}

In this study, eight impacts (global warming, ozone layer depletion, abiotic depletion, acidification, eutrophication, photochemical ozone production, noise, and vibration) were defined as impact categories used to evaluate environmental impacts in building construction. Figure II shows a schematic configuration of the method to evaluate the environmental impacts in building construction that were presented in this study. The impact categories expressed in black are parts calculated based on existing LCA methodologies, and those expressed in red represent the local impacts reflected additionally by the characteristics of building construction activities.

\section{A. Global Impact Category}

\section{1) Global Warming Potential (GWP)}

The Intergovernmental Panel on Climate Change (IPCC) presented characterization factors (CFs) to define greenhouse gases, such as $\mathrm{CH} 4, \mathrm{~N} 2 \mathrm{O}$, HFCs, PFCs, SF6, and $\mathrm{CO}_{2}$, and standardized each greenhouse gas based on $\mathrm{CO}_{2}$ gas [25]. CML 2001, EDIP 2003, and Hong et al. (2012) apply CFs presented by IPCC as a method to calculate global warming potential (GWP). In this study, the midpoint impact category indicator (CI) on global warming based on $\mathrm{CO}_{2}$ is calculated using CFs for a 100year time horizon presented in IPCC 2007. EPS 2000 presents impact factors (IFs) on the AoP that can occur due to $\mathrm{CO}_{2}$, as shown in Table IV [24]. Accordingly, the environmental load unit (ELU) according to AoP can be calculated by applying IFs in Table IV to GWP calculated in accordance with IPCC 2007. IFs presented in Table IV are values in which EUR is converted into KRW through the method mentioned in Section 3.2.

\section{2) Ozone layer depletion potential (ODP)}

The World Meteorological Organization (WMO) presented various characterization factors on the ODP of various emissions, such as CFC-11, CFC-14, halons, and HCFC-141b [26]. In addition, the five LCIA methods examined earlier based on the problem-oriented approach all applied characterization factors presented by WMO to calculate ODP. Accordingly, this study suggests calculating the midpoint impact category indicators on the ODP using CFs presented by WMO. The EPS 2000 presents IFs on the AoP that can occur due to CFC-11, as shown in Table IV [24]. Accordingly, ELU according to AoP can be calculated applying IFs in Table IV to the calculated ODP.

\section{3) Abiotic stock depletion potential (ADP)}

CML 2001 presented CFs on abiotic resources, such as Lead ore, Fe-ore along with fossil fuels such as hard coal, soft coal, or crude oil [1]. By using CFs on various resources, as presented by CML 2001, the midpoint impact CI, or ADP can be calculated. In addition, EPS 
2000 also presented IFs on various abiotic stocks [24]. Accordingly, it is possible to calculate environmental costs using IFs in Table IV, as presented in EPS 2000. The characterization factors of ADP presented in Table IV are examples of IFs on various resources presented in EPS 2000.

\section{B. Regional Impact Category}

\section{1) Acidification Potential (AP)}

Hauschild and Wenzel (1998) defined emissions, such as $\mathrm{CH} 4, \mathrm{~N} 2 \mathrm{O}$, HFCs, PFCs, SF6, and SO2, as emissions that cause acidification, and they presented CFs to represent the degree in which each type of emission affects acidification, based on SO2 (Hauschild and Wenzel, 1998).
In general, the degree of acidification varies, depending on the characteristics of pollutants and the atmospheric environment of the emission region, but comprehensive application is available through CFs on numerous emissions presented by Hauschild and Wenzel (1998). In this regard, CML 2001 and Hong et al. (2012) applied CFs presented by Hauschild and Wenzel (1998) to calculate AP by various emissions. This study suggests using general CFs presented by Hauschild and Wenzel (1998) to calculate the AP in building construction. EPS 2000 presents IFs to represent the degree in which SO2 has an effect on the AoPs in terms of monetary values, as shown in Table IV (Steen, 1999). Accordingly, the environmental costs by AP can be calculated by applying IFs in Table IV to AP calculated by the method suggested by Hauschild and Wenzel (1998).

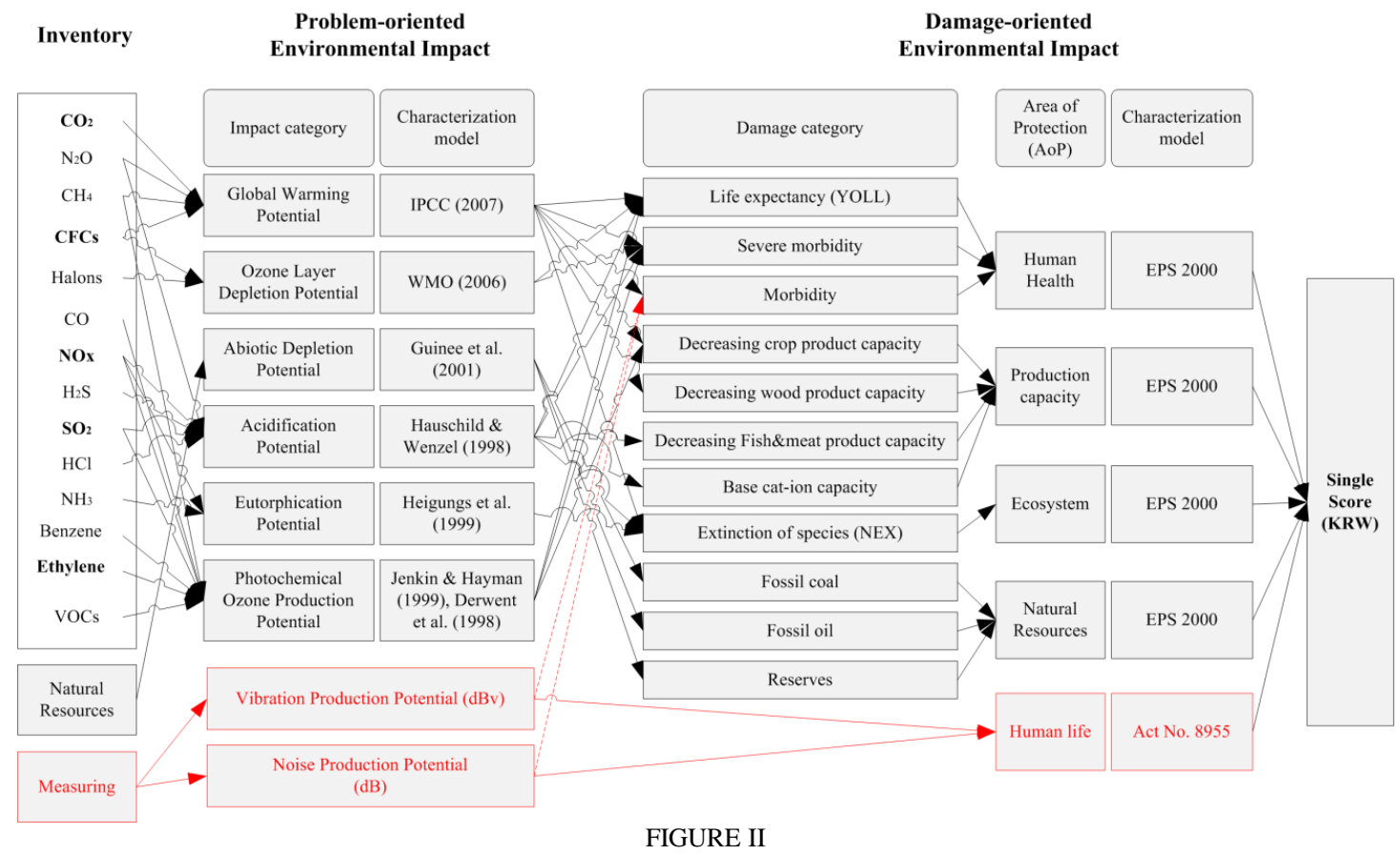

FRAMEWORK FOR ASSESSING ENVIRONMENTAL IMPACTS IN BUILDING CONSTRUCTION

\section{2) Eutrophication Potencial (EP)}

Heigungs et al. (1992) defined phosphate $\left(\mathrm{PO}_{4}{ }^{3-}\right)$, nitrogen oxide $\left(\mathrm{NO}_{\mathrm{x}}\right)$, ammonia $\left(\mathrm{NH}_{3}\right)$, and $\mathrm{COD}$ as emissions that cause eutrophication, and presented CFs to represent the degree in which each type of emission causes eutrophication based on $\mathrm{PO}_{4}{ }^{3-}$. This study suggests calculating EP in building construction using CFs presented by Heigungs et al. (1992). EPS 2000 presents IFs so that damages on the AoPs caused by $\mathrm{NO}_{\mathrm{x}}$ can be calculated, as shown in Table IV [24]. Accordingly, the environmental costs by EP can be calculated by applying IFs in Table IV to EP, calculated using CFs of Heigungs et al. (1992). However, the result calculated through the method of Heigungs et al. (1992) is the value based on phosphate $\left(\mathrm{PO}_{4}{ }^{3-}\right)$, and the value presented in EPS 2000 is the one based on $\mathrm{NO}_{\mathrm{x}}$. Accordingly, EP calculated into $\mathrm{kg}-\mathrm{PO}_{4}{ }^{3-}$ must be converted into $\mathrm{kg}-\mathrm{NO}_{\mathrm{x}}$. Since Heigungs et al. (1992) present CF of " 1 " and " 0.35 " in phosphate $\left(\mathrm{PO}_{4}{ }^{3-}\right)$ and nitrogen oxide $\left(\mathrm{NO}_{\mathrm{x}}\right)$, respectively, the final environmental costs can be calculated by dividing the calculated results by 0.35 .

\section{3) Photochemical Oxidation Potential (POCP)}

Derwent et al. (1998) and Jenkin and Hayman (1999) defined ethylene, benzene, methane, etc., as emissions that cause photochemical oxidation, and they presented CFs to represent the degree in which each type of emission causes photochemical oxidation. CML 2001 used the method of Derwent et al. (1998) and Jenkin and Hayman (1999). This study suggests calculating POCP in building construction using CFs presented in CML 2001. In addition, EPS 2000 presents IFs on the damages caused by ethylene [24]. Accordingly, environmental costs can be calculated by applying IFs in Table IV to POCP. 
TABLE V

ASSIGNMENT OF CHARACTERIZATION FACTORS FOR EACH IMPACT CATEGORY

\begin{tabular}{|c|c|c|c|c|}
\hline Scope & $\begin{array}{l}\text { Midpoint Impact } \\
\text { Category }\end{array}$ & Damage Category & $\begin{array}{c}\text { Area of Protection } \\
(\text { AoP })\end{array}$ & $\begin{array}{l}\text { Impact Factor } \\
\text { (ELU/kg-unit) }\end{array}$ \\
\hline Global & Global warming & Life expectancy (YOLL) & human health & 64.40 \\
\hline \multirow[t]{12}{*}{ Impacts } & $\left(\mathrm{CO}_{2 \mathrm{eq}}\right)$ & Severe morbidity & human health & 33.73 \\
\hline & & Morbidity & human health & 6.26 \\
\hline & & Decreasing crop product capacity & Ecosystem production capacity & 0.11 \\
\hline & & Decreasing wood product capacity & Ecosystem production capacity & -1.55 \\
\hline & & Extinction of species (NEX) & ecosystem & 1.32 \\
\hline & Ozone layer depletion & Life expectancy (YOLL) & human health & 27286.88 \\
\hline & $\left(\mathrm{CFC}-11_{\mathrm{eq}}\right)$ & Severe morbidity & human health & 66879.60 \\
\hline & Abiotic stock depletion & $\mathrm{Al}$ reserves & Natural resources & 419.43 \\
\hline & $(\mathrm{kg})$ & Ba reserves & Natural resources & 4251.63 \\
\hline & & Natural gas & Natural resources & 1050.97 \\
\hline & & Fossil coal & Natural resources & 47.58 \\
\hline & & Fossil oil & Natural resources & 483.44 \\
\hline Regional & Acidification & Life expectancy (YOLL) & human health & 2.28 \\
\hline \multirow[t]{8}{*}{ Impacts } & (SO2) & Severe morbidity & human health & 1.21 \\
\hline & & Decreasing fish\&meat product capacit & Ecosystem production capacity & 1.13 \\
\hline & & Base cat-ion capacity & Ecosystem production capacity & 14.90 \\
\hline & & Extinction of species (NEX) & ecosystem & 1.24 \\
\hline & Eutrophication $\left(\mathrm{NO}_{\mathrm{x}}\right)$ & Extinction of species (NEX) & ecosystem & 19.23 \\
\hline & Photochemical oxidation & Life expectancy (YOLL) & human health & 974.53 \\
\hline & (ethylene) & Severe morbidity & human health & $2.17 \times 10^{9}$ \\
\hline & & Decreasing crop product capacity & Ecosystem production capacity & 696.50 \\
\hline
\end{tabular}

Note: one ELU signifies one KRW.

\section{Local Impact Category}

\section{1) Vibration Potential (VP)}

Shin Hyo-seong et al. (2007) suggested vibrationinduced coefficients on various construction equipment, such as excavators, bulldozers, pile drivers, and concrete pump cars, to predict the vibration level caused by the use of the construction equipment and blasting works [27]. The vibration occurrence index shows the vibration level occurring $7.5 \mathrm{~m}$ from the source of vibration. Accordingly, it is possible to predict the duration and size of the vibration occurring in the construction site by using the vibration-induced coefficients by construction equipment, as presented by Shin Hyo-seong et al. 4 (2007). In addition, by using formulas and criteria suggested by Amick (1999), the vibration level according to distance can be calculated [28]. Meanwhile, since the vibration occurring in the construction site can cause damages to human health, decrease in the productivity of livestock, and destruction of buildings, many countries around the world have determined the acceptable vibration levels [29]. In addition, the National Environmental Dispute Resolution Commission (2008) presented the compensation criteria for damages due to excessive vibration levels in accordance with the Environmental Dispute Adjustment Act. Accordingly, it is possible to calculate the environmental costs of vibration by applying the compensation criteria for damages to the vibration level by distance.

\section{2) Noise potential (NP)}

As in the case with vibration, Shin Hyo-seong et al. (2007) presented noise-induced coefficients on various construction equipment to predict the noise level caused by the use of the construction equipment and blasting works [27]. Accordingly, it is possible to predict the duration and size of the noise occurring in the construction site by using the noise-induced coefficients by construction equipment, as presented by Shin Hyoseong et al. (2007). In addition, by using the formulas and criteria suggested by Amick (1999), the noise level according to distance can be calculated (Amick, 1999). Meanwhile, since noise occurring in the construction site can cause damages to human health, decrease in the productivity of livestock, and destruction of buildings, many countries around the world have determined the acceptable noise levels. In addition, it is possible to calculate environmental costs of noise using the compensation criteria for damages due to excessive noise levels, as presented by the National Environmental Dispute Resolution Commission (2008).

\section{CONCLUSION AND DISCUSSION}

The Korean construction industry aims to widen the construction of green buildings as part of its efforts to reduce environmental impacts. To promote the green buildings, the environmental values of the products must be clearly presented. In this regard, this study attempted to suggest the framework in assessing the environmental impacts in building construction. Communication, the characteristics of construction, and stakeholder acceptance were all taken into consideration. In addition, existing LCIA methods and previous researches related to environmental impacts of construction activities were reviewed. 
Consequently, eight environmental impact categories, divided into global impact, regional impact, and local impact, were defined, and the methods in evaluating each impact category were presented. Global warming potential, ozone layer depletion potential, and abiotic stock depletion potential were included among the global impacts. Acidification potential, eutrophication potential, and photochemical oxidation potential were regional impacts. Vibration potential and noise potential were defined as local impacts. The evaluation method on the environmental impacts is important, but the communication of the evaluation results is also important. That is, environmental impacts, as evaluated through assessment methods, should be made easily understandable for both general public and stakeholders. In a related move, the assessment framework suggested in this study includes the method of presenting the eight environmental impacts in monetary values.

By using the assessment framework presented in this study, it is possible to clearly evaluate the environmental impacts of buildings. In addition, the evaluation results are expected to be utilized in obtaining the environmental values of the building, thereby contributing to the spread of green buildings.

However, the assessment framework presented in this study has several limitations. First, the methods used to assess noise and vibration potentials in the design phase and converted into monetary values were presented, but the standards in presenting the final assessment results into a single score have not yet been suggested. In addition, since there are no methods in predicting dust emissions in the design phase and there are no criteria in representing the damage caused by dust as monetary value, dust, which was considered as an important environmental impact in existing studies, was not included in the framework. Lastly, the "GDP per capita" that reflects the difference in economic levels was taken into consideration to convert weighting factors presented in EPS 2000, however, the level of awareness on environmental issues was not reflected. Accordingly, the three limitations mentioned earlier will have to be complemented by conducting further studies.

\section{ACKNOWLEDGEMENTS}

This research is supported by a grant from High-Tech Urban Development Program (11CHUD-G03) funded by the Ministry of Land, Transport and Maritime affairs, South Korea.

Note: This paper was originally published as the conference paper in the ICCEPM 2013 and awarded as one of the best papers. Through a rigorous review process, the paper has been invited to be a special version of JCEPM.

\section{REFERENCES}

[1] J.B. Guinee, et al., "Life cycle assessment: An operational guide to the ISO standards", Ministry of Housing, Spatial planning and the Environment (VROM) and Centre of Environmental Science Leiden University (CML), 2001.
[2] R.H. Crawford, "Life Cycle Assessment in the Built Environment", New York: Spon Press, 2011.

[3] Y. Kim, H. Cha, K. Kim, D. Shin, "Evaluation Method of Green Construction Technologies Using Integrated LCC and LCA Analysis", Korea Journal of Construction Engineering and Management, vol. 12, no. 3, pp. 10, 2011.

[4] W. Trusty, "Integrating LCA into LEED - Working group A Interim Report \#1", US Green Building Council, p. 11. 2006.

[5] S. Tae, C. Baek, S. Shin, "Life cycle $\mathrm{CO}_{2}$ evaluation on reinforced concrete structures with high-strength concrete", Environmental Impact Assessment Review, vol. 31, no. 3, pp. 253-260, 2011.

[6] T. Hong, C. Ji, H. Park, "Integrated model for assessing the cost and $\mathrm{CO} 2$ emission (IMACC) for sustainable structural design in ready-mix concrete", Journal of Environmental Management, vol. 103, pp. 1-8, 2012.

[7] C. Baek, S. Tae, S. Roh, J. Lee, S. Shin, "A Study on the Requisite Elements of $\mathrm{LCCO}_{2}$ Evaluation System at Planning Stage of Building", Korea Journal of Construction Engineering and Management, vol. 12, no. 3, pp. 11, 2011.

[8] ILCD, "International reference life cycle data system handbook. Framework and requirements for life cycle impact assessment (LCIA) models and indicators", in The International reference life cycle data system hand book, $1^{\text {st }}$ ed., Joint Research Centre, 2010.

[9] American National Standards Institute, "Environmental management - Life cycle assessment - Principles and framework", ANSI/ISO 14040 - 1997, 1997.

[10] J.M.C. Teixeira, "Construction site environmental impact in civil engineering education", European Journal of Engineering Education, vol. 30, no. 1, pp. 51-58, 2005.

[11] Z. Chen, H. Li, C. Wong, "Environmental Management of Urban Construction Projects in China", Journal of Construction Engineering and Management, vol. 126, no. 4, pp. 320-324, 2000.

[12] Z. Chen, H. Li, C. Wong, "Environal Planning: Analytic Network Process Model for Environmentally Conscious Construction Planning", Journal of Construction Engineering and Management, vol. 131, no. 1, pp. 92-101, 2005.

[13] R.J. Cole, "Building environmental assessment methods: assessing construction practices", Construction Management and Economics, vol. 18, no. 8, pp. 949-957, 2000.

[14] L.Y. Shen, V.W.Y. Tam, "Implementation of environmental management in the Hong Kong construction industry", International Journal of Project Management, vol. 20, no. 7, pp. 535-543, 2002.

[15] T. Hong, C. Ji, K. Jeong, "Environmental Impact Assessment of Buildings based on Life Cycle Assessment (LCA) Methodology", The Korean journal of construction engineering and management, vol. 13, no. 5, p. 9, 2012.

[16] American National Standards Institute, "Environmental Management-Life Cycle Assessment-Life Cycle Impact Assessment", ANSI/ISO 14042-2000, 2000.

[17] J.C. Bare, P. Hofstetter, D.W. Pennington, H.A. Udo de Haes, "Life cycle impact assessment workshop summary. Midpoints versus endpoints: The sacrifices and benefits", International Journal of Life Cycle Assessment, vol. 5, no. 6, pp. 319-326, 2000.

[18] O. Jolliet, M. Margni, R. Charles, S. Humbert, J. Payet, G. Rebitzer, R. Rosenbaum, "IMPACT 2002+: A new life cycle impact assessment methodology", The International Journal of Life Cycle Assessment, vol. 8, no. 6, pp. 324-330, 2003.

[19] J.C. Bare, G.A. Norris, D.W. Pennington, T. McKone, "TRACI The tool for the reduction and assessment of chemical and other environmental impacts", Journal of Industrial Ecology, vol. 6, no. 3-4, pp. 49-78, 2003.

[20] M. Hauschild, J. Potting, "Spatial differentiation in Life Cycle impact assessment - The EDIP 2003 methodology", Danish Ministry of the Environment; Environmental Protection Agency, 2005.

[21] J. Bare, "TRACI 2.0: the tool for the reduction and assessment of chemical and other environmental impacts 2.0", Clean Technologies and Environmental Policy, vol. 13, no. 5, pp. 687696, 2011.

[22] H.J. Althaus, et al. "Implementation of Life Cycle Impact Assessment Methods", Dubendorf: Swiss Centre for Life Cycle Inventories, 2007. 
[23] M. Goedkoop, R. Spriensma, "The Eco-indicator 99 A damage oriented method for Life Cycle Impact Assessment", $3^{\text {rd }}$ ed., PRé Consultants B.V., 2001.

[24] B. Steen, "A systematic approach to environmental priority strategies in product development (EPS). version 2000 - models and data of the default method", Centre for Environmental Assessment of Products and Material Systems, 1999.

[25] Intergovernmental Panel on Climate Change (IPCC), "IPCC fourth assessment report: Climate Change 2007”, IPCC, 2007.

[26] J.S. Daniel, G.J.M. Velders (Lead Authors), A.R. Douglass, P.M.D. Forster, D.A. Hauglustaine, I.S.A. Isaksen, L.J.M. Kuijpers, A. McCulloch, T.J. Wallington, "Halocarbon scenarios, ozone depletion potentials, and global warming potentials", Chapter 8 in Scientific Assessment of Ozone Depletion: 2006, Global Ozone Research and Monitoring Project-Report No. 50, pp. 572, World Meteorological Organization, Geneva, Switzerland, 2007.

[27] H.S. Sun, Y.M. Park, J.H. Lee, Y.H. KIm, J.C. Bang, "Study of improving Noise Level and Vibration level compution method by investigating environmental dispute case", National Environmental Dsipute Resolution Comission of South Korea, 2007.

[28] H. Amick, "Frequency-dependent soil propagation model", Proceedings of SPIE Conference on Current Developments in Vibration Control for Optomechanical Systems, Denver, Colorado, 1999.

[29] H.J. Hwang, "Problems and measures of Noise and Vibration permission criteria by analyzing blast works associated civil", Korean Society of Civil Engineers (KSCE), vol. 44, no. 11, pp. 36$42,1996$. 